nating mines; it describes the apparatus employed by him, and the difficulties that prevented its practical application, and continues as follows :-

"I substituted the voltaic ignition of a platina wire for the disruptive discharge. Any one who has seen the common lecture-table experiment of igniting a platina wire by the voltaic current nearly to the point of fusion, will have no doubt of the brilliancy of the light emitted; although inferior to that of the voltaic arc, yet it is too intense for the naked eye to support, and amply sufficient for the miner to work by. My plan was then to ignite a coil of platinum wire as near to the point of fusion as was practicable, in a closed vessel of atmospheric air, or other gas, and the following was one of the apparatus which I used for this purpose, and by the light of which I have experimented and read for hours :-A coil of platinum wire is attached to two copper wires, the lower parts of which, or those most distant from the platinum, are well varnished; these are fixed erect in a glass of distilled water, and another cylindrical glass closed at the upper end is inverted over them, so that its open mouth rests on the bottom of the former glass; the projecting ends of the copper wires are connected with a voltaic battery (two or three pairs of the nitric acid combination), and the ignited wire now gives a steady light, which continues without any alteration or inconvenience as long as the battery continues constant, the length of time being of course dependent upon the quantity of the electrolyte in the battery cells. Instead of making the wires pass through water, they may be fixed to metallic cups wellluted to the necks of a glass globe.

The spirals of the helix should be as nearly approximated as possible, as each aids by its heat that of its neighbour, or rather diminishes the cooling effect of the gaseous atmosphere; the wire should not be too fine, as it would not then become fully ignited; nor too large, as it would not offer sufficient resistance, and would consume too rapidly the battery constituents; for the same reason, i.e. increased resistance, it should be as long as the battery is capable of igniting to a full incandescence."

The memoir concludes with the description of experiments on the illumination power of this contrivance under different conditions.

\section{THE ENGLISH ECLIPSE EXPEDITION}

THE following communication, under date lat. N. $37 \cdot 8$, long. E. II IO, April 27, has appeared in the Daily Newe, from the special correspondent of that paper with the English Eclipse Expedition :-

Your correspondent so far has not had a very easy time of it, although it must be confessed his difficulties have been in no way connected with lack of material. Chronicling attempt; to advance beyond the frontiers of the known must always be a pleasant task to the chronicler, who is thus enabled to be among the first to reap the rich intellectual rewards always gained, or nearly always gained, in such forays. But when the task brings him in full view of other interests, and especially when it compels him to observe phenomena for himself, a correspondent's task may become complicated beyond measure, and not only the embarras de richesses, but even a mental revision of his instructions, however precise they may have been, may give him trouble. Thus, in the present case, my clear duty is to keep pace with the thoughts and doings of the Eclipse party now on the Kaisar-i-Hind, between Gibraltar and Malta; but am I therefore to be blind to the fact that each $P$. and $O$. ship does not leave Gravesend with two tons of telescopes and eyes to use them, and that the infusion of a scientific party into the general run of passengers on this the most important of England's seaways, cannot but cause what our American cousins would call a "ripple" on the ordinary routine of ship-life.
Those who have made their way to the far East many times, and who are therefore quite familiar with this routine, will at once recognise the possibility that at first such rarce aves were looked at askance. Was there not at least some strange power of divining secrets in sextants, spectroscopes, and cameras brought now and then, and with a kind of furtive air, from hidden recesses? And this being so, what conduct was more natural on the part of the non-scientific members of the party, than that they should show a keen anxiety to assure everybody that they at least knew next to nothing of science-in short, that though they might deplore these strange and aberrant tendencies, they were powerless to interfere, even if the studies were less harmless than they believed them to be. This, at first, of course confirmed the general impression, but it did not take long for the ice to melt ; the strange feeling soon wore off, and after a fierce gale which the Kaisar-i-Hind encountered in the Bay of Biscay had abated, the keenness of everybody on board to hear something of a world of marvels new to most of them, and the anxiety of every servant of the $P$. and $O$. Company, from captain to boatswain, to help, whenever help was needed, were the predominant features.

The delight of the Somali boys at being photographed was a sight to see, their broad grins being in strange contrast with the evident anxiety of the Arabs among the crew to escape the influence of such a possible evil eye. While this is going on in one part of the ship, the reflection of the summer sun shimmering from a thousand Mediterranean waves through which the noble ship ploughs her way on an even keel is utilised to show the wondrous work which has already been done by the spectroscope. Nor are the other worlds, still left to conquer, forgotten in the demonstration; among them, those secrets of the Sun which it is hoped may be unveiled during the coming precious seventy seconds. And this brings me to the proper subject matter of the present letter. What, then, are the astronomers going to do? or, to put it more modestly, what are they going to try to do? Before a categorical answer can be given to this question there is some preliminary matter to be got over; we have, in fact, to consider the changes in thought and methods introduced by ten years of work. A volume might be written on this, but a very brief exposé is really all that is required on the present occasion. The brilliant achievements of physical astronomers in the domain of solar physics during the last twenty years bave dealt in the main with the chemical and physical construction of the atmosphere of our central luminary; that is, those parts of it which are furthest from the centre. In fact, it has been a question of meteorology, and not a question of geology, to use terrestrial equivalents. One of the first things made absolutely certain was that the outer atmosphere for tens and perhaps hundreds of thousands of miles above the surface of the round orb we generally see and call the Sun, is intensely hot-hot enough to have its clouds built up of vapour of iron, as in our own air we have clouds built up of the vapour of water. Next, as the work went on, two things happened. First, certain and sure evidence was obtained that the outer atmosphere extended much farther from the sun than had been previously supposed by those most competent to form a just opinion ; and, further, while the extent of the atmosphere was thus engaging attention, the chemical inquiry had been carried so far that we thought we were justified in saying, not only that the sun's atmosphere contained just such substances as ours would do if our little earth were suddenly turned into a mass of vapour, but that certain substances occupied such and such positions in the atmosphere, while others were to be sought for elsewhere.

Thus outside all, it was imagined, there was a substance about which we know nothing here, because we cannot find anything which produces the same spectrum. Inside 
this, at mid-height in the sun's atmosphere, we got indications about which there could be no mistake-we were in presence of hydrogen : incandescent hydrogen, be it observed, which plays as important, or indeed a still more important part in the solar air than nitrogen does in our omn. Next it was imagined that close to the sun itself there was a vaporous sea containing all the other substances which had been detected by the spectroscopemagnesium, calcium, iron, barium, cobalt, nickel, and some twenty other bodies termed "elements" by the chemist, because he cannot reduce them to a condition of greater simplicity. As the sum total of these inquiries, then, we had some such idea of the sun's atmosphere as this : Physically it was incandescent, of enormous extent, very irregular in outline, its extent and outline varying almost every time it could be observed. Chemically it was built up of substances known to terrestrial chemistry; it was very simple at top, and very complicated at bottom. This mental image was the joint product of both laboratory and eclipse work. The solar spectrumthat is, the beautiful rainbow ribbon which is produced when light from the sun is made to pass through a prism -enabled us even in our laboratories, without a telescope, to study the chemistry of the sun's atmosphere as a whole, but such work as this localised nothing. Further, the outer atmosphere is so dim as compared with the intensely brillin nt interior nucleus, that it, like the stars in the daytime, is put out, and remains invisible so long as the sun itself is in a position to illuminate our upper air. In this we have the use of total eclipses, for at such times the moon prevents the sunlight from falling on our atmosphere, and the sun's atmosphere shines out in all its weird splendour, as the stars show themselves when the light of day is withdrawn. It is fair to add, that there is a method which enables us to study the chemistry and even the meteorology of the very brightest portion of the sun's atmosphere, called the chromosphere, without waiting for an eclipse, but still, every allowance being made, it should be now clear that to study the physical attributes of the atmosphere as a whole, we are strictly limited to total eclipses. So much, then, for our brief exposé. There is still some more ground to be gone over before the question with which we set out is answered. What was the sum total of the work done during the last eclipse-that observed in the United States in 1878 , with a wealth of instrumental appliances such as had never been used before? How did it deal with our received notions? Did it endorse them or demolish them?

It certainly endorsed them in the main, while it enabled us to accumulate a vast amount of new knowledge on many important points, and showed us how every effort should be made to secure these precious records. Among other things, it intensified the difference between eclipse and eclipse, for the spectroscopic record of the outer corona-as the exterior atmosphere is sometimes called -differed very considerably from the one secured in $187 \mathrm{r}$, and it was a noteworthy fact that the eclipse of I87I happened when there were most spots on the sun, while that of 1878 took place when there were fewest. said "in the main." But during the eclipse one observation was made, which in the light of former laboratory work suggested that after all there was a rift in the lute, and that our view of the solar economy might be much more wrong than we had any idea of. Since 1878 that same laboratory work has been continued, and a long series of observations of the spectra of sun-spots has been made, and the tendency of all this extra eclipse-work has all been in one direction. We are now face to face with the idea that, in the hottest part of the sun, the temperature is so high that our so-called elementary bodies are broken up into simpler ones, and that the reason that the sun seems to contain so many of our terrestrial elements is simply that both in the sun and in a powerful electric spark these bodies are really broken up into their finer constituents, the spectral lines of these finer constituents being observed in both cases. Now it is obviously the duty of men of science, if there be any tests of this new view, any crucial observations possible during an eclipse, to apply these tests, to make these observations, as soon as possible-not, of course, to the neglect of the old methods of attack, but, if possible, in addition to them ; and as the problem is one of such general interest, and one which is sure to be keenly debated, as many records independent of personal error or personal bias should be obtained as possible. These permanent records, to which reference has been made, are of course photographs, and here we are brought face to face with another fact; we have not only a new view to test, but we have new photographic processes to apply to test it, as well as to obtain a series of records comparable with those secured during prior eclipses. We have in this case an instance of the way in which an observation, apparently trivial, is at last seized hold of and made to furnish a stepping-stone for a further advance in scientific inquiry. It is now many years since Faraday, experimenting on gold leaf, which is green when a bright light is observed through it, found that he could change its colour, and he fancied that this might be taken to indicate that the gold in the leaf did not consist of particles all of the same size, but that they existed of almost an infinite series of finenesses. This was in the pre-spectroscopic days. When the spectroscope could be brought to bear, it became apparent that two orders of fineness only were required to produce all the colours observed by Faraday, and Mr. Lockyer soon produced other evidence which went to show that we were here in presence of a general law. From this time we heard the words "blue molecules" and "red molecules"-terms invented to indicate that in the same chemical substances there were some molecules with such physical attributes that they were turned to and could therefore absorb blue light, while others were made active by red light falling upon them.

Capt. Abney, in a series of painstaking researches, has shown that precisely those salts of silver employed by photographers obey this general law, and hence we can now use blue light and red light indiscriminately, and so, for the first time we can photograph the red end of the spectrum of the sun's external atmosphere. Nor is this all; other advances in the photographic art enable us now to replace minutes by seconds in the time of exposure ; indeed, in these days of "instantaneous" processes, the difficulty often lies in exposing the plate for a time short enough to the influence of the light. It is as well to insist upon this point, as in the eclipse of next month the totality or period during which the moon entirely covers the sun is very short; but short as it is, it is more than made up for by the increased rapidity of the processes to be employed. Now, the most important phenomena to be recorded, whether by eye or photography, are, first, the spectrum of the lowest stratum of the sun's atmosphere revealed to us at the moment of disappearance and reappearance of the sun by a sudden flashing out of bright lines; next, the spectrum of the outer atmosphere, best observable at mid-eclipse ; and then the extent and structure of the atmosphere itself. Now it is imagined, that if the new view to which reference has been made is correct, the spectrum of the lower stratum will differ from what it is supposed to be, and we say supposed to be, because up to the present time the observations have been of such a general nature that it has been impossible to be quite certain about details. The intention this time is to observe a small portion of the spectrum with great minuteness, so far as the eye observations go, while an attempt will be made to actually photograph the flash of bright lines, and obtain a reference spectrum afterwards by obtaining a photograph of the solar spectrum on the same plate after the eclipse is over.

Among the most interesting observations made during 
the total eclipse of 1878 -duly chronicled in the Daily Neres at the time--was one by which Prof. Newcomb demonstrated a tremendous extension of the corona in the direction of the plane of the sun's equator, or very near it. It will be important to see, whether on the present occasion the extension will be so great, especially since Dr. Siemens has thrown down the gauntlet to astronomers by his bold speculations touching the circulation of the solar gases. Such, then, are some of the things which the Eclipse Expedition is going to do, or going to try to do. If all goes well, I shall be able in my next letter to tell your readers something of a definite nature as to the actual camping-ground and the local arrangements in Egypt.

The following telegram from its special correspondent is given in Tuesday's Daily News:-

\section{Sohag, Monday}

The preparations are complete for the eclipse on Wednesday, thanks to the assistance rendered by the representatives of the Egyptian Government to the English, French, and Italian observers alike. The weatber is apparently settled. There is little probability of duststorms. The greatest heat experienced is 108 in the shade. The temperature is now cooler. The English party will probably return by Carthage, leaving Suez on the 3 Ist.

\section{$A L G A^{1}$}

$\mathrm{I}^{\mathrm{T}}$ is little more than a year since the Latin edition of Dr. Agardh's work on the "Morphology of the Florideæ" was noticed in the pages of NATURE. The author now sends us another contribution to the systematical study of algæ. The present is, however, not a distinct work, but a continuation of a series of Essays or Monographs, the first instalment of which appeared in vol. ix. of the Transactions of the University of Lund, in the year 1872 . The subjects of the first instalment were the genera Caulerpa and Zonaria, and the classification and description of the Australian species of certain tribes of Sargassum.

The present work consists of essays on the CHORDARIEE, and on some of the DICTYOTEÆ. Although it bears a Swedish title, it is written in Latin. It commences with a monograph of the family Chordarieæ, which is entirely reconstructed, and is enlarged by the introduction of several new genera. Under the present arrangement it comprises seventeen genera.

From the increased activity recently shown by British algologists, whose exertions have been rewarded by the discovery of many species of Algæ new to these shores, it would seem desirable to mention more particularly a few of the changes which have been made in the present work by Dr. Agardh in the classification of some of the plants of the olive series of Algæ.

Beginning with Elachistea, as the author, restoring the old spelling, prefers to call it, we find that this genus is removed to the CHORDARIEÆ. This is in accordance with the views of Dr. W. H. Harvey, expressed in the "Phyc. Brit. Tit." $E$. fucicola. This genus is especially interesting from thelfact that out of the nine species, seven are British. E. velutina (of the "Phyc. Brit." pl. xxviii. B), removed by Thuret to Streblonema, is placed by Dr. Agardh in his new genus Herponema (see p. 55).

The next genus, Myriocladia, includes $M$. Loveni, an extremely rare species, which has been obtained growing on oysters in deep water in the Baltic, and which Dr. Agardh ("Sp. Alg.", p. 53) states was found by the late Mr. Borrer on the Sussex coast; it has not, however, been met with by succeeding observers; neither has Dr. Agardh seen the plant in other collections. The name of this rare plant does not occur in the published lists of

1 Til Algernes Systematik. Nya bidrag af J. G. Agardh (Andra Afdelningen) Lunds Univ. Årsskrift. Tom. xvii. (4to., pp. 134).
Algæ found by Mr. Borrer. A representation, mauch enlarged, of some of the details of the plant, will be found on Pl. I, Fig. 3.

The genus Mesogloia is now restricted to two species, $M$. Mediterranea and $M$. vermicularis. $M$. virescens. is removed to Eudesme, of which another species inhabits Tasmania and South Australia. Chordaria divaricata and Mesogloia Griffithsiana are now respectively Castagnea divaricata and C. Griffithsiana. The observations on the structure and fruit of the epiphytic plants, which constitute the genera Myrionema and Herponema, will be interesting to British algologists.

Among the new Algæ which have been recently added to the British Marine Flora, is the handsome plant found by Mr. G. W. Traill, in the Firth of Forth, and issued to British collectors under the name of Dictyosiphon Hippuroides. The plant was first described and figured by Lyngbye in the "Hydrophytologiæ Danicæ," under the name of Scytosiphon Hippuroides; then, in Agardh's "Sp. Gen. et ord. Alg.", vol. i. p. 66, as Chordaria flagelliformis, var. B. Hippuroides. Areschoug subsequently distributed dried specimens of the plant, and published (Bot. Notiser, I873, No. 6., and Obs. Phycol., iii. 1875) descriptions of it under the name of Dictyosiphon Hippuroides. In the present work Dr. Agardh maintains the opinion he had expressed in "Sp. Alg." more than thirty-three years ago, that the Scyt. Hippuroides of Lyngbye is a form of Chord. flagelliformis, and not a Dictyosiphon. He supports his views by a minute description of the structure of the frond, and gives at length (pp. 67-70) his reasons for differing in opinion from his old friend Dr. Areschong. As a proof of the care with which Dr. Agardh conducted his examination of the plant, it may be mentioned that he describes and names six forms of it, including among them, Scyt. Hippuroides, Ll., and Scyt. tomentosus of Fl. Dan. and Lyngb. British algologists will find this part of Dr. Agardh's work particularly interesting.

Among the Algæ which have been recently added to the British Marine flora are Phlaospora tortilis (Rupr.) Aresc., and Dict. (Coilonema) mesogloia, Aresc.; it may be mentioned incidentally that Dr. Agardh considers both Phlæospora and Coilonema as distinct genera.

The DicTYoTe E.--The author commences with preliminary remarks on the limits of the family, and the structure and fructification of the different genera (pp. 77-83). Then follows an elaborate essay on the genus Dictyota (pp. 83-92); and after that a description of the species, and the tribes under which they are arranged. Of the twenty-six species, one only, $D$. dichotoma, is a native of our shores. Six other species are referred to Dilophus, J. Ag., and two to Glossophora, J. Ag.

The genus Spatoglossum, Kg., includes Taonia Solierii, 1: Schroderi, and two others. Then follow a few observations on Taonia atomaria. Patina is treated at greater length. To this succeed elaborate observations on the structure and fructification of Zonaria (pp. I20I3I), and some remarks on certain species. This part of the work, it must be observed, is supplementary to the article on Zonaria in the first part of the "Bidrag," p. 45 , before referred to, in which the several species are described.

It may here be remarked that the Zonaria collaris of the "Phyc. Brit." has no claim to be considered as a native of the British Isles. It is found in the Mediterranean and Adriatic, and occasionally in Granville Bay, on the French coast. It is not a Zonaria, but a Cutleria.

The work concludes with some observations on the species of Halyseris.

In the selection of the preceding subjects for remark, the writer has been guided by the interest which, it was thought, would be taken in them by British algologists; it must, however, be observed that the work has also many points of interest as regards Australia, Tasmania, and New Zealand. Among the species belonging to the 